\title{
A atividade intelectual Como TESTEMUNHO SOLIDÁRIO?
}

Rosana Kohl Bines

\begin{abstract}
RESUMO
Este ensaio discute os impasses teóricos que se colocam para a tarefa crítica no contexto do pós-guerra, em especial as relações entre o crítico-empático e as narrativas traumáticas ao qual está exposto. Investiga, também, a possibilidade da solidariedade em uma época em que o repertório humanista está desacreditado devido a sua suposta cumplicidade com políticas nacionalistas e colonialistas. $\mathrm{O}$ texto procura pensar qual seria a tarefa da literatura, da arte e do pensamento crítico em geral diante da irrepresentabilidade do sofrimento.
\end{abstract}

\section{PALAVRAS-CHAVE}

Shoah, testemunho, o intelectual, ética, solidariedade.

Dentre as muitas certezas que ruíram com a Shoah - o holocausto judaico perpetrado pelo estado alemão nazista - talvez nenhuma outra tenha preocupado tanto pensadores contemporâneos quanto a viabilidade mesma da atividade crítica no pós-guerra. As dúvidas que rondam a empreitada intelectual se relacionam a uma certa crise no ato de testemunhar. Eu não me refiro aqui ao âmbito da literatura testemunhal per se, à crise daqueles que efetivamente sofreram as atrocidades do holocausto e precisaram elaborar o trauma para resgatar formas precárias de lembrar e de narrar. Refiro-me, sim, à crise que acomete os "retardatários," aqueles que não viveram diretamente a experiência dos campos, aqueles que estão situados temporalmente depois do evento, mas que se sentem ainda assim implicados nas feridas abertas pela Shoah, instigados a confrontá-las, a prestar testemunho do passado para o presente, através de uma reavaliação ativa de questões ligadas, por exemplo, ao estatuto da memória, da representação, do próprio sujeito, em face ao aniquilamento destas categorias na cena devastadora do holocausto.

Esta situação singular de "atraso" em relação ao evento da Shoah desloca a questão do testemunho para além do registro autorizado da vítima ou do sobrevivente, em direção ao lugar duvidoso ocupado pelo observador distante. Lugar duvidoso porque, nas palavras do crítico americano Geoffrey Hartman, a testemunha retardatária "está exposta simultaneamente ao trauma e à ansiedade de não empatizar o bastante."

\footnotetext{
${ }^{1}$ Hartman. Shoah and Intellectual Witness, p. 42. Todos os trechos traduzidos no presente ensaio são de minha responsabilidade.
} 
Tal injunção traz à tona a pergunta: quão perto do sofrimento humano a prática intelectual se permite chegar sem resvalar para o outro lado?

Como nos alerta Hartman, há sempre o risco de excessiva identificação por parte do crítico para com aqueles que sofreram a experiência desumanizadora dos campos de concentração. Empatizar em demasia compele à apropriação indevida do trauma alheio algo não apenas condenável em termos éticos, como também um desserviço à atividade intelectual, tendo em vista a convicção de que certo distanciamento crítico seja fundamental à autonomia do ato reflexivo. Se endossarmos a tese, um tanto consensual, de que de fato a prática intelectual se beneficia da atitude de não empatizar demais, por que falar em ansiedade com relação à disposição de não empatizar o suficiente com os traumas da Shoah?

Sondar as fontes de tal ansiedade significa confrontar alguns impasses teóricos que se colocam para a tarefa crítica no contexto do pós-Shoah. Em primeira instância, a questão da empatia intelectual diante dos traumas do holocausto pede pelo retorno de uma linguagem afetiva, assim como de uma constelação de conceitos "profundos" como o de solidariedade, dor, sofrimento, morte, esperança, para ficar com alguns - conceitos que costumamos enfileirar sob a tão desgastada rubrica do "humano." Posto que o que está realmente em pauta quando se propõe a palavra "empatia" como chave para qualificar certa atitude teórica em frente à Shoah é a atenção do crítico para com esta dimensão profundamente humana da experiência traumática. É a disposição do crítico para a solidariedade com histórias de perdas incomensuráveis. Falar de empatia crítica em relação a catástrofes históricas, é sempre bom lembrar, não é o mesmo que reivindicar para a prática intelectual um discurso lacrimoso. Não é tarefa do crítico reproduzir ou "encenar" a fala vitimada. Há uma diferença fundamental entre os termos "acting out" e "working through," tal como Freud a concebeu em seu célebre estudo "Luto e Melancolia." Esta distinção conceitual tem sido muito cara aos estudos dedicados a pensar os traumas da Shoah e o processo de luto pelas perdas ali envolvidas. Segundo Freud, para que haja um trabalho efetivo de luto (Trauerarbeiten), é preciso existir um sentido de separação entre a pessoa enlutada e o objeto de afeição, cuja perda se lamenta, de forma que o enlutado possa elaborar a falta do outro, sem perder de vista os contornos do próprio "eu." Se, no entanto, se estabelece uma relação simbiótica entre o enlutado e o objeto ausente, de modo que o outro é percebido como parte constitutiva do "eu", então a melancolia sobrevém. A melancolia é a vivência repetitiva de uma dor narcísica, já que aquilo que está inexoravelmente perdido é entendido como parte inerente ao próprio ego do enlutado.

A distinção entre "acting out" e "working through" é bastante pertinente à consideração das relações entre o crítico-empático no pós-guerra e as narrativas traumáticas ao qual está exposto. Em seu estudo sobre os discursos do luto na cena do pós-holocausto, Eric Santner se apóia na tese freudiana para reclamar a necessidade de um contexto intersubjetivo no trabalho de luto, através da presença de um analista empático, que coparticiparia do espaço discursivo, onde a perda pudesse vir a ser elaborada simbólica e afetivamente. ${ }^{3}$ Santner argumenta que a presença de um interlocutor empático introduz

\footnotetext{
${ }^{2}$ Freud. Mourning and Melancholia, p. 244-401.

${ }^{3}$ Santner. Postwar/Post-Holocaust/Postmodern: Some Reflections on the Discourses of Mourning, p. $1-30$.
} 
uma dimensão de alteridade ao processo muitas vezes compulsivo e solitário da vítima do trauma, que encena repetidamente o choque traumático através da memória ou do sonho. A oportunidade de elaboração solidária da perda se torna possível justamente pela presença de uma figura testemunhal distinta da pessoa enlutada, com a qual a experiência traumática seja vivenciada para além do círculo repetitivo da melancolia e em direção a uma cena de fortalecimento do sujeito, para que, desapegado do objeto perdido, possa reinvestir em novos laços de afeição.

Sem pretender forçar uma analogia plena entre o papel do analista no trabalho do luto e o papel do crítico na abordagem das narrativas da Shoah, o que me parece fundamental como ponto de toque entre estas duas situações singulares é a disposição da figura testemunhal para a solidariedade com o sofrimento alheio, o que implica a mobilização de estratégias de linguagem e categorias de pensamento que não desprezem desde logo a ordem dos afetos. Prestar testemunho daquilo que se escuta ou se lê significa não passar por cima do pathos humano que acompanha uma catástrofe de tamanha proporção. Não se trata tanto de uma questão de sensibilidade, mas sobretudo de ética.

Neste sentido, Zygmunt Bauman justifica o seu livro Modernity and the Holocaust em face à "compulsão intelectual e obrigação moral" ${ }^{4}$ de responder à sabedoria desta sobrevivente: "A coisa mais cruel acerca da crueldade é que ela desumaniza suas vítimas antes mesmo de destruí-las. E a batalha mais árdua é permanecer humano em condições inumanas." ${ }^{5}$

Sem pretender ultrapassar a linha divisória que distingue o sobrevivente da testemunha "retardatária," há algo sobre a natureza desta batalha - a de permanecer humano em condições inumanas - que reproduz também a situação do intelectual-pós-guerra-comotestemunha-solidária. O pensador búlgaro-francês Tzvetan Todorov formulou o dilema com grande precisão: "Como conciliar esta perda de ilusões sobre o homem, por um lado, e manter o homem como foco de nossas ações, por outro?"6

Levando a interrogação de Todorov adiante, como é possível sustentar o Humanismo como paradigma operacional no confronto e oposição às atrocidades cometidas na Shoah, quando a própria Shoah tornou suspeitos os ideais humanistas? Que sentido atribuir a uma palavra como "solidariedade" no contexto do pós-guerra, por exemplo, quando se sabe que "solidariedade" foi usada tantas vezes como instrumento coercitivo contra a vida e a integridade de judeus, homossexuais, ciganos, excluídos do pacto "fraternal" da Volksgemeinshaft alemã??

Uma primeira resposta ao impasse requer o estabelecimento de diferenças entre a tradição humanista abalada pela Shoah e outras formas de humanismo, ainda em curso, ainda hesitantes, debatendo-se, por um lado, com o sentido de consciência histórica, no que tange às trajetórias intelectuais pelas quais não devemos mais passar, e por outro, com o imperativo moral de configurar novas constelações teóricas que fomentem modelos de

\footnotetext{
${ }^{4}$ Bauman. Modernity and the Holocaust, p. 208.

${ }^{5}$ Bauman. Modernity and the Holocaust, p. 208.

${ }^{6}$ Todorov. Letter in Homage to Primo Levi.

${ }^{7}$ Geoffrey Hartman trata da questão das formas degeneradas que a idéia de fraternidade assumiu durante o Terceiro Reich em seu ensaio "Shoah and Intellectual Witness", p. 43.
} 
coexistência, solidariedade, tolerância e diálogo entre os diferentes - contra a violência de discursos e políticas totalitárias.

A dificuldade e o desafio embutidos nesta dupla imbricação se acirram pela ausência de uma linguagem à altura da tarefa. Por um lado, o repertório humanista se encontra em ruínas, metodicamente desconstruído, sob a alegação de sua cumplicidade com políticas nacionalistas e colonialistas, cuja violência a linguagem homogeneizadora do universalismo humanista teria ajudado a encobertar. Por outro lado, o que surge na contramão das falácias do humanismo, sobretudo nos discursos da desconstrução, é uma espécie de poética das impossibilidades - de representar, de lembrar, de narrar, de significar, de constituir-se como sujeito. Este cenário de ausências, destituído do peso ontológico da tradição humanista, aposta no potencial crítico da experiência fragmentária e errante, que busca anular qualquer projeto de totalização simbólica. O maior problema em se converter prontamente esta poética da ausência e da errância em ética combativa contra regimes de autoridade e autenticidade é que não há aí lugar previsto para a dimensão (profunda) do afeto, imprescindível ao acercamento crítico das narrativas da Shoah. Que tipo de testemunho intelectual contra a barbárie é possível elaborar a partir de teorias críticas, em que, nas palavras ácidas de Frederic Jameson, "já não há mais o eu presente para atualizar o sentimento?" ${ }^{8}$ Este eu solar, autocentrado, sempre idêntico a si mesmo, é antagonizado pelo sujeito descontínuo, fraturado, em permanente deslocamento. Não é que se negue a este sujeito errante e incompleto a capacidade para o afeto. A esfera dos sentimentos é plenamente compatível com as turbulências próprias à condição descentrada. O que provoca o "esvaecimento do afeto" ${ }^{9}$ neste cenário contemporâneo, feito de esfacelamentos e precariedades, é menos a enunciação do sujeito como ser fraturado, do que sua enunciação como ser de linguagem, como entidade eminentemente discursiva. Quando se configura o sujeito como ser de papel, se está a um passo de tratar o sofrimento humano como um problema estrutural de linguagem. E de tratar a morte - sofrimento maior da humanidade - como um evento lingüístico, uma espécie de ausência inerente a todo discurso. A tarefa da literatura, sob este ângulo, é a de prestar testemunho ao vazio estrutural, sem nunca pretender preenchê-lo com a presença integral do sentido, mas antes expor o vazio como vazio, como lugar vacante, como não-origem, geradora ela mesma de sentidos incompletos, deslocados e diferidos. A tarefa da literatura é a de prestar testemunho a este sofrimento estrutural, causado pela dificuldade em se escrever aquilo que é de fato impossível de ser escrito. Tal aporia da linguagem ganha versão compacta nas palavras de Jean-François Lyotard: "ela [a arte] não diz o indizível, mas diz que é incapaz de dizê-lo."10

É no contexto do pós-Shoah, diante da premissa de que o holocausto é indizível, que Lyotard elabora a escritura como narrativa do irrepresentável - algo análogo aos tabus estudados por Freud, tais como a castração, o incesto, o parricídio, enfim, tudo aquilo

\footnotetext{
pela lógica da superfície.

${ }^{10}$ LyotaRd. Heidegger and "the jews", p. 47.

${ }^{11}$ LyotaRd. Heidegger and "the jews", p. 19.
}

${ }^{8}$ Jameson. Postmodernism or the Cultural Logic of Late Capitalism, p. 15.

9 Peço de empréstimo a Jameson a expressão "esvanecimento do afeto" (waning of affect), que o autor utiliza em sua discussão sobre o pós-modernismo (1990). Jameson condiciona certa indiferença contemporânea com relação ao afeto à cultura pós-moderna da imagem e do simulacro, regrada 
que, segundo Lyotard, "não chegou a ocorrer (...) porque não é passível de representação," 11 mas tudo aquilo que, ainda assim, permanecerá sempre como traço ou resto. A presença daquilo que foi esquecido ou reprimido, porque não pode de nenhuma forma ser lembrado ou representado, porque é impossível a qualquer um admiti-lo em pensamento - a presença deste esquecimento é o que, para Lyotard, move a escritura no pós-Shoah. Lyotard faz uma distinção bem clara entre o entendimento convencional da palavra esquecimento enquanto falha de memória, e este outro tipo de esquecimento, que constitui o imemorial em linguagem, aquilo que não é representável ou passível de síntese, porque "desafia imagens e palavras." 12 Esta outra modalidade de esquecimento atesta a impossibilidade da memória e da re-presentação, ou seja, a impossibilidade da escritura como manifestação de presenças. Ignorar esta impossibilidade e insistir em qualquer resgate afirmativo da Shoah - seja através de sua dramatização em romances, filmes ou poemas - seria domesticar o evento, no sentido de subjugá-lo às leis ordinárias da memória:

Sempre que representamos, inscrevemos algo na memória, e isto pode parecer uma boa defesa contra o esquecimento. O que ocorre, acredito, é justamente o oposto. Só aquilo que já foi inscrito pode, no sentido corrente do termo, ser esquecido, porque é passível de ser apagado. Mas o que não está inscrito (...) não pode ser esquecido, não se oferece ao esquecimento e permanece presente "apenas" como um afeto que não se pode sequer qualificar, como um estado de morte na vida do espírito. ${ }^{13}$

O que Lyotard reivindica nesta passagem é uma espécie de escritura a contrapelo. Somos convocados a vislumbrar o beco sem saída da linguagem. Relembrando a aporia já mencionada: "ela [a arte] não diz o indizível, mas diz que é incapaz de dizê-lo." Não há absolutamente qualquer concessão aos termos deste impasse. A tarefa rigorosa da literatura, da arte e do pensamento crítico em geral é prestar testemunho do irrepresentável. Nenhuma outra possibilidade é aventada. Estamos diante do que Maurice Blanchot nomeou como "escritura do desastre"14 - uma escritura debruçada sobre seus próprios abismos, preocupada em nomear uma crise que jamais chegará a transcender.

Creio que esta aporia é de fato impossível de ser superada, porque, afinal, para Lyotard, a Shoah não é apenas um desastre histórico, mas um desastre desde sempre presente no

\footnotetext{
${ }^{12}$ Lyotard. Heidegger and "the jews", p. 26.

${ }^{13}$ Lyotard. Heidegger and "the jews", p. 26.

${ }^{14}$ Maurice Blanchot escreveu um livro entitulado L'écriture du désastre, onde oferece uma meditação fragmentada sobre os efeitos devastadores da Shoah na linguagem. A seguinte frase resume de forma pungente a visão de Blanchot: "Le désastre ne met pas en question, mais lève la question, la fait disparaître" ( $\mathrm{O}$ desastre não coloca em questão, mas suspende a questão, a faz desaparecer). Neste livro, Blanchot enfrenta as dificuldades de forjar uma linguagem que dê conta do inimaginável, ou seja, da experiência catastrófica que destrói as condições de inteligibilidade, destituindo o escritor de uma gramática ou ethos adequados à tarefa. Blanchot intensifica a noção de desastre, sugerindo que a Shoah tornou inviável tanto a capacidade do sujeito de narrar a experiência de sua própria exterminação, quanto a capacidade de narrar a experiência da destruição da própria experiência. Ainda que Blanchot e Lyotard compartilhem a gramática da escritura como desastre, a escrita de Blanchot carrega um sentido de urgência e de desespero por aquilo que a palavra não é capaz de dizer que é muito distinta da abordagem um tanto distanciada de Lyotard, com seu nomadismo abstrato, imaterial e apático. Blanchot. L' écriture du désastre, p. 50.
} 
cerne da escritura, atualizado toda vez que se mobiliza a linguagem. Diante do Holocausto e da morte de milhões de seres humanos, Lyotard redescobre que a morte já existe desde sempre no interior da linguagem, como um carimbo negativo, selando uma marca indelével no texto. Esta marca lacunar, que se toma como condição inexorável de toda escritura, não permite que se vislumbre qualquer outro caminho para o testemunho no pós-Shoah, senão aquele comprometido com os termos inflexíveis da aporia, formulada como um apelo moral irrefutável: "Sejamos todos testemunhas do irrepresentável."15

Sejamos também testemunhas do caráter dogmático de um pensamento que prescreve de antemão um sentido, ainda que negativo, para a narrativa do pós-Shoah o de sondar o irrepresentável - um traço que se toma por imemorial, uma espécie de condição perene da linguagem, que a Shoah tornaria apenas flagrante na história. Em última instância, a posição que Lyotard reivindica enquanto testemunha do irrepresentável não se insere em qualquer temporalidade específica, tampouco se dirige a qualquer público determinado: "Vamos prestar testemunho, e de novo, e para ninguém, do pensamento como desastre." 16 A crítica mais severa que com freqüência se faz a abordagens desconstrutivistas é que elas transformam o exercício crítico em circunlocuções compulsivas em torno do recorrente topos do silêncio, da ausência, do vazio. Hayden White qualifica o gesto desconstrutivista como aquele que "levanta a questão crítica, apenas para ter a satisfação impiedosa de contemplar a impossibilidade de algum dia vir a resolvê-la." 17 Cabe perguntar em que medida a fórmula radical de Lyotard sobre a impossibilidade do narrar se enquadraria na avaliação cética de White? Até que ponto a escritura como desastre é um projeto que vigora apenas no espaço preservado da vida acadêmica, mas cujos paradoxos e demandas radicais dificilmente seriam tolerados por sujeitos históricos, para quem o "desastre" é uma experiência por demais concreta? Como abordar, por exemplo, as reivindicações de inúmeros povos por território, pela manutenção da identidade nacional, por raízes, por memória, por representação? Deveríamos desprezar sumariamente tais reivindicações, sob o rótulo de arcaísmo, tratando-as como manifestações de impulsos nostálgicos e ingênuos, a serviço de discursos nacionalistas, que estaríamos todos moralmente obrigados a combater?

O pensamento de Lyotard não oferece qualquer subsídio para confrontar estas questões, já que se empenha prioritariamente em desmistificar estas reivindicações, a ponto de torná-las inoperantes para o contexto do pós-Shoah. O impulso desmistificador nunca chega a considerar novas possibilidades de se dialogar com estes ideários, novas formas de se teorizar sobre "raízes," "lar", "identidade," por exemplo. A atitude é de descarte, não de engajamento, no sentido de uma reavaliação crítica destes conceitos.

A propósito destas questões, penso particularmente no livro de Lawrence Langer, intitulado Holocaust Testimonies: The Ruins of Memory, ${ }^{18} \mathrm{com}$ sua cuidadosa análise dos muitos modos de lembrar, que as vítimas do holocausto mobilizam: memória profunda, memória angustiada, memória humilhada, memória menor... Talvez este seja um

\footnotetext{
${ }^{15}$ Lyotard. The Postmodern Condition: A Report on Knowledge, p. 82.

${ }^{16}$ Lyotard. The Inhuman, p. 203. (Grifo meu).

${ }^{17}$ White. Theories of History, p. 7.

${ }^{18}$ LANGer. Holocaust Testimonies: the Ruins of Memory.
} 
comentário óbvio demais, mas não abro mão de fazê-lo neste contexto, pois assim como há várias formas de lembrar e de esquecer a Shoah, há também vários modos de testemunhar e de registrar o evento. A argumentação de Lyotard nos leva a obliterar tal diversidade e a considerar apenas uma possibilidade, como se fosse a única correta, a única moralmente digna, a única capaz de corresponder às exigências radicais da aporia que Lyotard não cessa de glosar: "o que permanece possível é prestar testemunho à impossibilidade da representação." 19 Trair tal princípio e ousar dizer o indizível ou representá-lo de alguma maneira é para Lyotard uma forma perversa de testemunho, que não atinge outro objetivo senão o de reproduzir o crime nazista da exterminação: "Uma vez atestados, o sofrimento e o indomável estão como que destruídos. Eu quero dizer que quanto se testemunha, também se extermina. A testemunha é um traidor."

A linguagem manipulativa com a qual Lyotard induz o leitor a descartar outras possibilidades de testemunho nos compele a presumir que atestar o irrepresentável é a única maneira de salvar o sofrimento da exterminação. Mas será? Minha hipótese aponta para o sentido inverso, qual seja, o de que o sofrimento é destruído pelas próprias estratégias que pretendem salvá-lo. Eu desenvolverei este ponto através de uma consideração breve sobre o filme Shoah, de Claude Lanzmann, citado por Lyotard como exercício exemplar de testemunho à impossibilidade de testemunhar.

Em linguagem evocativa da prosa de Lyotard, Shoshana Felman descreve o filme Shoah como um "produto de uma busca obstinada pela lembrança, mas pela lembrança que se autonega, contraditória, conflituosa, lembrança de uma amnésia. O testemunho hesita em dizer e ao mesmo tempo diz a impossibilidade de dizer." ${ }^{21}$ Os métodos cinematográficos que Lanzmann emprega para dramatizar tal amnésia para o público implica em uma opção consciente por omitir qualquer representação gráfica de imagens de guerra. Na ausência de tomadas documentais, ou de qualquer encenação visual da guerra, o que aparece nas dez horas de projeção do filme é uma série de testemunhos fragmentários, povoados por imagens de paisagens desertas e cemitérios silenciosos, onde não se avistam corpos. Não há sequer música ou quaisquer efeitos de sonoplastia. Absolutamente nenhum recurso dramático que desvie nosso olhar desta "amnésia secreta," desta "ausência radical" que remete ao aniquilamento do sujeito que testemunha, assim como ao aniquilamento de todas as linguagens para a viabilização do testemunho. Tudo na tela gravita em torno da órbita desta "obsessão," 22 como Lanzmann a define, de revelar os efeitos destruidores da Shoah, os quais são compreendidos apenas por default, através da reiteração da

\footnotetext{
${ }^{19}$ LyOtARD. Heidegger and "the jews", p. 47.

${ }^{20}$ Lyotard. The Inhuman, p. 204.

${ }^{21}$ Felman e Laub. Testimony: Crisis of Witnessing in Literature, Psychoanalysis, and History, p. 224. (Grifo meu).

${ }^{22}$ Em entrevista concedida a Shoshana Felman, Claude Lanzmann fala de suas obsessões em relação à filmagem de Shoah: "Eu não tinha qualquer conceito (do Holocausto); eu tinha obsessões, o que é diferente (...) A obsessão do frio (...). A obsessão da primeira vez. O primeiro choque. A primeira hora dos judeus no campo, em Treblinka, os primeiros minutos. Eu sempre perguntarei sobre a primeira vez (...). A obsessão pelos últimos momentos, a espera, o medo (...).” Transcrito no livro de Felman e Laub. Testimony: Crisis of Witnessing in Literature, Psychoanalysis, and History, p. 223.
} 
impossibilidade mesma de demonstrá-los ou captá-los em imagens ou palavras. É justamente esta obsessão, este olhar intenso, que nunca se permite desviar do abismo aberto pela Shoah, a grande conquista de Lanzmann, sob a ótica de Lyotard:

O filme Shoah de Claude Lanzmann (...) raramente oferece um testemunho onde o irrepresentável do holocausto não esteja indicado, seja por um momento apenas, na alteração do tom de voz, na garganta apertada, choro, lágrimas, uma testemunha que se desvia da câmera, um distúrbio no tom da narrativa, um gesto descontrolado. Daí entendermos que estas testemunhas impassíveis, quem quer que elas sejam, estão certamente mentindo, "encenando," escondendo alguma coisa. ${ }^{23}$

É interessante notar como Lyotard constrói seu comentário. Primeiro, lista algumas manifestações de afeto flagrante (choro, lágrimas, etc.), para de imediato descartá-las em favor daquilo que elas estariam encobertando, ou seja, a amnésia secreta, a cena primária do esquecimento, o irrepresentável.

O que é em última instância relevante nestas manifestações de afeto é justamente aquilo que não está nelas manifesto. Em outras palavras, estes sentimentos nunca são validados pelo que demonstram em presença, mas por sua instrumentalidade potencial em revelar, por default, os horrores do holocausto. O gesto crítico de Lanzmann, o qual Lyotard corrobora em sua própria escritura, é reiterar obsessivamente o absurdo que é tentar representar um evento irrepresentável. Quaisquer outras considerações, incluindo manifestações flagrantes de sofrimento e dor, se submetem a esta compulsão urgente de formular a aporia. Por esta razão, faço reservas ao argumento de Shoshana Felman de que a coleção de testemunhos fragmentários, apresentados no filme Shoah, atestaria a "invalidação de todas as definições, de todos os parâmetros de referência, de todas as respostas conhecidas. ${ }^{24} \mathrm{O}$ que parece escapar a tal avaliação é que de fato o filme constrói cuidadosamente um paradigma para se ler a Shoah e busca validá-lo, pelos recursos de reiteração e redundância. Isto significa dizer que os testemunhos na tela convergem para a afirmação da mesma premissa básica acerca da impossibilidade da representação. A posição de Lanzmann como testemunha "retardatária" dos testemunhos que registra em seu filme engendra também um certo desprezo por tudo que estas vozes testemunhais possam revelar para além do recorte preestabelecido, qual seja, o da irrepresentabilidade do evento. Este é o grande risco que atravessa o impactante filme de Lanzmann. Para o cineasta, prestar testemunho desta aporia intransponível se sobrepõe muitas vezes ao ato de testemunhar o drama humano que excede o impasse teórico.

A posição de Lyotard como testemunha "retardatária" da Shoah está muito próxima à de Lanzmann, na medida em que sua compulsão em teorizar o esquecimento na escritura faz com que se esqueçam todas as narrativas da Shoah que não reiterem a tese sobre a impossibilidade da representação. Não pretendo sugerir com isto que a teoria deva dar conta da totalidade de narrativas pertinentes à Shoah. Não se trata de reclamar uma postura onipotente ao fazer teórico. Ao contrário, trata-se de apontar a onipotência presente na atitude de impor um modelo seletivo e purificado de testemunho a uma constelação de testemunhos muito mais abrangente e diversa. É certo que a questão da impossibilidade

\footnotetext{
${ }^{23}$ LyOtARD. Heidegger and "the jews", p. 26.

${ }^{24}$ Felman e Laub. Testimony: Crisis of Witnessing in Literature, Psychoanalysis, and History, p. 224.
} 
de representação é extremamente relevante aos estudos da Shoah. É inegável também que este é um tópico que emerge da experiência palpável - e do sofrimento - de escritores como Paul Celan, cuja poesia marca de forma indelével as ausências na linguagem, toda ela infiltrada pela morte que está em toda parte: "Ein Wort - du weißt / eine Leiche" (Uma palavra, tu sabes / um cadáver.). ${ }^{25}$

Não é que queira desconsiderar nem o pathos humano nem a produtividade teórica que acompanham as narrativas do irrepresentável, mas antes avaliar que modelos ou modos de testemunhar são gerados pela mistificação destas narrativas e a que custo.

A escritura do desastre acaba por validar uma forma muito particular de narrar e de lembrar, identificada, por sua vez, com um seleto grupo de escritores, cujas obras são elevadas à categoria de testemunhos exemplares do esfacelamento de todas as fundações tradicionais a partir das quais seria possível contar o acontecido:

Em oposição ao retorno à Germania prometida: Freud, Benjamin, Adorno, Arendt e Celan - estes grandes alemães não-alemães, judeus não-judeus - que não apenas questionam, mas traem a tradição, a mimesis, a imanência do desdobramento e sua raiz; para quem imigração, dispersão e a impossibilidade de integração tornam desesperador todo retorno. ${ }^{26}$

Daniel e Jonathan Boyarin são contundentes em sua crítica à seleção de Lyotard, já que esta listagem de autores esquece a grande maioria das vítimas do nazismo - judeus sem aura teórica, que não cabem no "modelo oficial já ratificado do judeu não-judeu, os Franz Kafkas e Walter Benjamins..."27 Mas não precisaríamos ir tão longe. Sugiro que nem mesmo os Franz Kafkas e os Walter Benjamins seriam capazes de corresponder às exigências radicais do pensamento nomádico, que desconhece todo retorno. Para ilustrar meu argumento, uma rápida visada em dois dos autores selecionados por Lyotard: Hannah Arendt e Theodor Adorno. Meu foco incidirá sobre o apego destes dois pensadores a um dos pilares da "Germania" ironizada por Lyotard - a Mutter Sprache alemã.

Em entrevista dada à televisão alemã, em 1964, publicada posteriormente no célebre livro O judeu como pária, Hannah Arendt responde à pergunta - "was bleibt?" - o que resta diante da experiência devastadora da guerra e do exílio forçado em solo americano? A resposta é direta: "A língua materna ... Sempre." ${ }^{28}$ Apesar de Arendt ter publicado inúmeras livros e ensaios em língua inglesa e ainda ter desenvolvido ao longo de sua estadia nos EUA

\footnotetext{
${ }^{25}$ Celan. Nächtlich Geschütz. Gesammelte Werke, p. 125.

${ }^{26}$ LYOTARD. Heidegger and "the jews", p. 93.

${ }^{27}$ Boyarin e Boyarin. Diaspora, Generation and the Ground of Jewish Identity, p. 720. A expressão "judeu não-judeu" foi primeiro cunhada por Isaac Deutscher em seu livro homônimo The NonJewish Jew, 1968. A alcunha se refere aos judeus assimilados da Europa, frutos do processo de Emancipação. Deutscher define o judeu não-judeu como aquele que teria desenvolvido a capacidade de combinar sua condição desenraizada e cosmopolita às suas raízes na tradição judaica, situandose assim na fronteira de várias culturas e discursos. O termo "judeu não-judeu" busca pensar a condição judaica enquanto traço moral, não condicionado à filiação nacional. $O$ "judaico" nestes termos é entendido tanto como elemento subversivo contra o poder e a convenção, quanto como signo de solidariedade em relação a todos os discriminados na história. Para uma caracterização do judeu em termos afins, elevado à categoria combativa de pária social e intelectual, ver Hannah Arendt, The Jew as Pariah: Jewish Identity and the Politics in the Modern Age.

${ }^{28}$ Arendt. The Jew as Pariah: Jewish Identity and the Politics in the Modern Age, p. 55.
} 
uma discussão teórica profunda sobre a instrumentalidade da língua alemã no planejamento e registro detalhado das atrocidades nazistas, resta um desconcertante sentimento de fidelidade a uma língua que ela jamais deixou de sentir como "materna" e "originária."

Um sentimento afim de afeição à língua atormenta o pensamento combativo de Theodor Adorno. Em uma palestra transmitida pela rádio alemã em 1965, Adorno enfrenta a pergunta "was ist Deutsch?" com a mesma atitude direta de Arendt: "O alemão é uma língua." ${ }^{29}$ Esta resposta aparentemente simples é o ponto de partida da crítica vigorosa de Adorno tanto ao mito germânico de uma língua pura quanto à política exclusivista que este mito autoriza. Ainda assim, em meio à argumentação cristalina de Adorno contra todo ideário lingüístico, fundado em essencialismos, o pensador explica o fracasso de seu exílio americano e seu decorrente retorno à Alemanha como uma questão de incompatibilidade lingüística. Adorno nunca se sentira "em casa" no idioma inglês e era constantemente tomado pela frustração de não conseguir transpor seus pensamentos para a língua estrangeira. Pressionado a justificar sua incapacidade de trabalhar na língua inglesa, Adorno reivindica para o alemão "uma afinidade eletiva especial para a filosofia, sobretudo para seu elemento especulativo." ${ }^{30}$ Seguimos com Adorno: "historicamente, através de um processo que ainda não foi devidamente analisado, a língua alemã adquiriu a capacidade de expressar algo acerca dos fenômenos que não se esgota no plano da materialidade, da positividade, do factível." Adorno se pergunta como é possível traduzir conceitos como Geist, Erfahrung ou Moment, "com todas as conotações que ressoam em alemão?"31 Esta espécie de "bônus metafísico" que Adorno concede a sua língua materna rivaliza com seu discurso usualmente combativo, contra a violência e exclusão geradas pelo mito da (Ur)Sprache alemã.

É fundamental marcar estas encruzilhadas teóricas, pois elas alertam para o fato de que há sempre um emaranhado de linguagens incompatíveis e simultâneas na sondagem da crise que é estar deslocado, tanto na língua quanto na geografia. Afirmações categóricas sobre o fim das tradições e das grandes narrativas devem dar lugar ao reconhecimento de que estes discursos fundadores não desaparecem simplesmente, mas permanecem ativos, com maior ou menor vigor, em um confronto dinâmico com novos paradigmas teóricos. A difícil tarefa, a meu ver, não é teorizar o desapego ou o desenraizamento radicais, como propõe Lyotard, mas sim teorizar pertenças simultâneas, ainda que tanta vezes paradoxais.

O intelectual solidário se coloca "entre" uma série de impasses, quando se dispõe tanto ao acercamento quanto à recusa do sofrimento alheio. De um lado, vigora a consciência de que algo de fato pereceu nos campos de concentração, que diz respeito à morte da solidariedade e dignidade humanas, da confiança básica do homem para com o seu próximo. De outro, o sentido da responsabilidade do pensamento na restauração destes canais de solidariedade. Mas como negociar velhas utopias para novas formações históricas e discursivas, de forma que não se restaurem simplesmente ideários já falidos? Como mobilizar idéias de comunidade, diálogo, tolerância, apostando na possibilidade renovada

\footnotetext{
${ }^{29}$ Adorno. On the Question: What is German?, p. 129.

${ }^{30}$ Adorno. On the Question: What is German?, p. 129.

${ }^{31}$ Adorno. On the Question: What is German?, p. 130.
} 
de coexistência entre os diferentes, sem incorrer no entusiasmo ingênuo por um discurso humanitário vazio? Como forjar modelos intelectuais que respeitem, preservem e articulem diferenças, mas nunca a ponto de convertê-las em fetiches de alteridade, impermeáveis ao diálogo e à troca cultural?

Há algo a respeito destas interrogações que pede a injeção de certa dose de utopia na litania de mortes e ausências que permeia a nossa era pós-Shoah. Retornando ao impasse crítico de Todorov - "Como conciliar esta perda de ilusões sobre o homem por um lado e manter o homem como foco de nossas ações pelo outro?" -, é revelador que esta pergunta figure em uma carta que Todorov escreveu em homenagem a Primo Levi, o escritor judeu-italiano, sobrevivente de campos de concentração, que cometeu suicídio após uma vida intensa dedicada a pensar a condição humana no Lager. Para Todorov, o imperativo ético de se preservar alguma forma de humanismo crítico no contexto do pós-guerra está intimamente ligado ao gesto de restituir uma dimensão de futuridade às nossas narrativas - contra a exterminação, contra a derradeira interrupção da morte.

É esta dimensão de futuro que parece estar fechada ao projeto teórico de Lyotard. Parece-me emblemático que Lyotard nunca mencione os suicídios de Walter Benjamin ou Paul Celan, por exemplo, cujas obras ele preserva em um patamar filosófico e moral tão elevado, a ponto de cristalizá-las em um estado de radicalidade pura, impermeável à realização mundana de que a morte é muito mais do que um vácuo textual. A insistência na questão da inevitabilidade do sofrimento e da morte como marcas textuais indeléveis impede a escritura de Lyotard de vislumbrar o futuro como interrogação, como pergunta em aberto, passível de transformação e intervenção. Reabrir esta dimensão utópica na elaboração de novas constelações teóricas significa correr riscos. Em que linguagem é possível articular um sentido ético de responsabilidade do pensamento para com a humanidade diante das retóricas já desgastadas das vanguardas modernas e de sua aposta fracassada no poder contestador da arte como agente de transformação social? Como assumir um compromisso de solidariedade intelectual diante da falência de tantos projetos coletivos dedicados à redenção da humanidade pela cultura e pela arte?

Prestar testemunho intelectual no pós-guerra está atrelado a esta encruzilhada, que exige, a um tempo, o olhar desconfiado em face das grandes utopias do passado - o que Andreas Huyssen chama de "no longer possibles" 32 - e o investimento utópico na elaboração de linguagens que tornem possíveis, para o tempo presente, algumas impossibilidades do passado. Tal exercício crítico exige um estado de alerta moral que não dá lugar nem ao entusiasmo ingênuo, nem ao ceticismo distanciado. Para Huyssen, "a questão não é eliminar a tensão produtiva entre política e estética (...) entre engajamento e a missão da arte. $\mathrm{O}$ objetivo é acirrar esta tensão, até mesmo para redescobri-la e redimensioná-la nas artes e na crítica." 33

\footnotetext{
32 Alguns dos "no longer possibles" citados por Huyssen são: o realismo, a representação, a subjetividade, a história. Huyssen. After the Great Divide: Modernism, Mass culture, Postmodernism, p. 208.

${ }^{33}$ Huyssen. After the Great Divide: Modernism, Mass culture, Postmodernism, p. 221.

${ }^{34}$ Clifford. Travelling Cultures, p. 109.
} 
É neste campo de tensão que a atividade intelectual no pós-Shoah deve se projetar. Não se trata mais de fixar um ponto a partir do qual teorizar, mas situar o crítico na encruzilhada de imbricações teóricas. Quando o antropólogo americano James Clifford propõe que se reformule a questão da identidade como "not so much where are you from, but where are you between?" 34 (algo como "não tanto de onde você é, mas entre o que você está?) - e faz uma aposta nas potencialidades críticas deste campo de tensão, de onde a atividade intelectual precisa confrontar e articular os impasses de sua condição "retardatária." Aquele que chega atrasado à cena tem a oportunidade de exercitar tanto o olhar retrospectivo quanto o prospectivo, lançando perguntas ao passado com vistas às perguntas abertas per seu presente.

Em frente às narrativas da Shoah, entre a ansiedade de "não empatizar o bastante" e o risco de "empatizar em excesso," entre a visada distante e a aproximação míope, há um longo intervalo, que não é feito de ausências, mas de percursos. Cabe ao intelectual solidário ousar os caminhos.

\section{A BSTRACT}

This essay discusses the theoretical impasses faced by artists and intellectuals in the post-war context, especially the relations between the empathetic critic and the traumatic narratives of his time. The text also investigates the prospects of solidarity in the present, when the humanist repertoire has been discredited due to its association with nationalist and colonialist policies. What, then, is the role of literature, the arts and critical thought when confronted with the impossibility of representing suffering and trauma?

\section{KEY WORDS}

Shoah, testimony, intellectuals, ethics, solidarity.

\section{REFERÊNCIAS BIBLIOGRÁFICAS}

Adorno, Theodor. On the question: What is German? Trad. Thomas Y. Levin. New German Critique. Wisconsin-Milwaukee: Holmes \& Meyer Publishers, n. 36, out. 1985, p. 121-131. Arendt, Hannah. The Jew as Pariah: Jewish Identity and the Politics in the Modern Age. New York: Schocken Books, 1978.

Bauman, Zygmund. Modernity and the Holocaust. New York: Cornell Press, 1996.

Blanchot, Maurice. L' écriture du désastre. Paris: Gallimard, 1980.

Boyarin, Daniel; Boyarin, Jonathan. Diaspora, Generation and the Ground of Jewish Identity. Critical Inquiry, n. 19, aug. 1993, p. 693-725.

Celan, Paul. Nächtlich Geschütz. Gesammelte Werke. Frankfurt am Main: Suhrkamp, 1986, p. 125.

Clifford, James. Travelling Cultures. Cultural Studies, 1992, n. 1, p. 96-116.

Deutscher, Isaac. The Non-Jewish Jew and Other Essays. Londres: Oxford University Press, 1968. 
Felman, Shoshana; Laub, Dori. Testimony: Crisis of Witnessing in Literature, Psychoanalysis, and History. New York and London: Routledge, 1992.

Freud, Sigmund. Mourning and Melancholia. The Standard Edition of the Complete Psychological Works of Sigmund Freud. Londres: Hogarth Press, v. 14, 1953-74.

Hartman, Geoffrey. Shoah and Intellectual Witness. Partisan Review, Boston, n. 1, jan. 1988.

Huyssen, Andreas. After the Great Divide: Modernism, Mass culture, Postmodernism. Bloomington and Indianapolis: Indiana University Press, 1986.

Jameson, Frederic. Postmodernism or the Cultural Logic of Late Capitalism. Durham: Duke University Press, 1990.

LANGer, Lawrence. Holocaust Testimonies: the Ruins of Memory. New Haven and London: Yale University Press, 1991.

Lyotard, Jean-François. Heidegger and "the jews". Trad. Andreas Michel e Mark Roberts. Minneapolis: Minnesota University Press, 1990.

Lyotard, Jean-François. The Inhuman. Trad. Geoffrey Bennington e Rachel Bowlby. Stanford: Stanford University Press, 1991.

Lyotard, Jean-François. The Postmodern Condition: A Report on Knowledge. Trad. Geoffrey Bennington e Brian Massumi. Minneapolis: Minnesota University Press, 1984.

Santner, Eric. Postwar/Post-Holocaust/Postmodern: Some Reflections on the Discourses of Mourning. Stranded Objects. Ithaca e Londres: Cornell University Press, 1999, p. 1-30. Todorov, Tzvetan. Letter in Homage to Primo Levi. [s.d.].

White, Hayden. Theories of History. (Los Angeles): William Andrews Clark Memorial Library, University of California, Los Angeles, 1978. 